\title{
Heterotaxy syndrome at adult age: A case report
}

\author{
Chen LW' ${ }^{1}$, Chou MC ${ }^{2}$ and Edmund C So ${ }^{3,4 *}$ \\ ${ }^{1}$ Department of Anesthesia, Chi Mei Hospital, Tainan, Taiwan \\ ${ }^{2}$ Department of Radiology, E-DA Hospital, I-Shou University, Kaohsiung City, Taiwan \\ ${ }^{3}$ Department of Anesthesia, An Nan Hospital, China Medical University, Tainan City, Taiwan \\ ${ }^{4}$ Department of Anesthesiology, China Medical University, Taichung City, Taiwan
}

\begin{abstract}
Heterotaxy syndrome, also known as Ivemark syndrome, is an uncommon disease characterized by cardiac vascular malformations, congenital asplenia or polysplenia, and abnormal arrangement of the chest and abdominal organs. We reported here, a young adult scheduled for emergency surgery due to right femoral shaft fracture. Surgery was postponed in suspicion of possible delayed intracranial hemorrhage (DICH). Computer tomorgraphy (CT) and cardiac catheterization revealed total occlusion of the Blalock-Taussig (B-T) shunt. The pathogenesis, clinical features, and management for patients with heterotaxy syndrome are discussed.
\end{abstract}

\section{Introduction}

Heterotaxy syndrome is an uncommon disease, with an incidence ranging from 1 in 6,000 to 1 in 20,000 live births [1,2]. This syndrome is characterized by major cardiac vascular malformations, congenital asplenia or polysplenia, and abnormal arrangement of the chest and abdominal organs. Here, we reported a patient with heterotaxy syndrome, who received palliative surgery during childhood for his complex cardiac abnormalities, and lived to the age of twenty. We reported this patient with images from sixty four slices CT for a comprehensive evaluation of this syndrome.

\section{Case description}

A twenty years old male, was admitted through Emergency Room (ER) at 10:30 pm due to traffic accident. The Glasgow Coma scale at the ER was $E_{4} V_{5} M_{6}$ and the vital signs were stable with blood pressure of $141 / 82 \mathrm{mmHg}$, tachycardia at 111 beats/min, respiratory rate at $19 / \mathrm{min}$, and body temperature at $36.5 \mathrm{Q}$. His arterial saturation when arriving in the ER was not disclosed in the chart. Past history of cardiac surgery (diagnosis: unknown) at the age of five was told by the patient and there was no limitation on physical activity thereafter. Physical examination revealed head injury with ecchymosis over left eye with symmetric pupil size. Laboratory data revealed hemoglobin $(\mathrm{Hb}) 17.2 \mathrm{gm} / \mathrm{dl}$; hematocrit (Hct) 55.7\%, mean corpuscle volume (MCV) $69.1 \mathrm{fl}$; Sodium 133.3 $\mathrm{mEq} / \mathrm{L}$, Potassium $3.07 \mathrm{mEq} / \mathrm{L}$, BUN $7 \mathrm{mg} / \mathrm{dL}$, Creatinine $0.8 \mathrm{mg} / \mathrm{dL}$, GOT $125 \mathrm{IU} / \mathrm{L}$, and GPT $59 \mathrm{IU} / \mathrm{L}$. Electrocardiogram showed sinus tachycardia and roentgen findings demonstrated no fracture of rib cage or spine except right femoral shaft fracture and centrally located gastric bubble (Figure 1). Brain CT revealed no intracranial hemorrhage, but fractures in left maxillary sinus and left lateral orbital wall. Abdomen CT was negative for internal bleeding, but centrally located stomach was noted (Figure 2A, B). After consultation by orthopedic surgeon, patient was scheduled for open reduction and internal fixation for his right femoral shaft fracture.

Pre-anesthesia evaluation at 5:00 am showed an acute ill-looking patient, coma scale $\mathrm{E}_{3} \mathrm{~V}_{3} \mathrm{M}_{5}$, with poor responses to questions and difficulty on localizing pain when we touched the left maxillary bone to evaluate the airway. Under the impression of possible DICH, surgery was postponed for six hours to observe for conscious and neurological changes. Three hours later, sudden onset tachypnea and desaturation of arterial blood gas $\left(\mathrm{PaO}_{2}: 43 \mathrm{mmHg}, \mathrm{PaCO}_{2}: 21.8 \mathrm{mmHg}\right.$, base excess:-1.6 , $\mathrm{FiO}_{2}: 100 \%$ ), were noted. The patient was sent to ICU for further evaluation. Repeated brain tomography and chest film at the ICU showed no DICH or remarkable pulmonary changes. Suspecting intracardiac shunting, cardiac echo was arranged which disclosed a large ventricular septal defect (VSD) and atrial septal defect (ASD) with right to left shunting; moderate pulmonary stenosis (estimated pressure gradient $50 \mathrm{mmHg}$ ); moderate tricuspid regurgitation and a B-T shunt with minimum flow. After interviewed with patient's mother and reviewing past medical record, he was found to be a victim of right isomerism with double outlet right ventricle (DORV) and received modified B-T shunt at the age of five. He had been hospitalized repeatedly for phlebotomy because of erythrocytosis.

The CT was performed on a sixty four slices scanner and revealed the patient to be a victim of heterotaxy syndrome (Table 1 \& Figure $3 \mathrm{~A}, \mathrm{~B})$ which included complex congenital heart disease, bilateral superior vena cava, bilateral right-sideness of the lungs with bilateral minor fissures and eparterial bronchi, absent spleen, central located liver, midline stomach, and juxtaposed inferior vena cava to the aorta, The presence of Howell-Jolly (HJ) bodies was compatible with asplenia. Total occlusion of the B-T shunt was confirmed both by sixty four slices CT and cardiac catheterization, which explained for the severe hypoxemia. Due to continuous severe hypoxemia, cardiac surgeon

Correspondence to: Edmund C So, Department of Anesthesia, An Nan Hospital, China Medica University, 66, Cheung Ho Road Section II, An Nan District, Tainan City, Taiwan, E-mail: edmundsotw@gmail.com

Key words: Blalock-Taussig (B-T) shunt, Heterotaxy syndrome

Received: November 20, 2017; Accepted: December 04, 2017; Published: December 08, 2017 


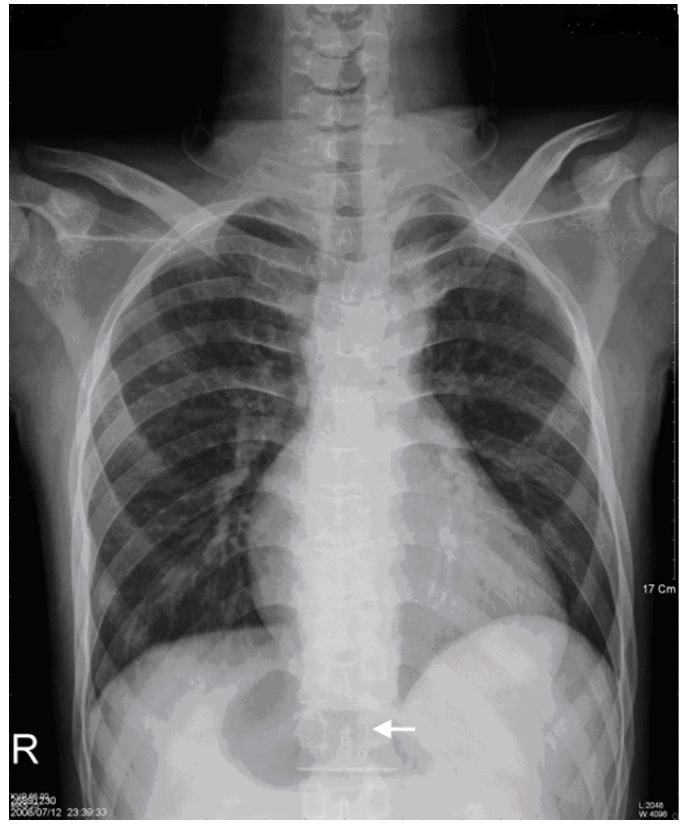

Figure 1. Plain chest film disclosed extraordinary cardiac shadow and centrally-located gastric bubble (white arrow)

Table 1. Heterotaxy syndrome in this patient.

\begin{tabular}{|l|}
\hline Cardiovascular anomalies \\
\hline Double outlet of right ventricle (DORV) \\
\hline Large ventricular septal defect (VSD) \\
\hline Common atrium \\
Severe pulmonary stenosis \\
\hline Bilateral superior vena cava (SVC) \\
\hline Interrupted inferior vena cava (IVC) \\
\hline Malformation of other organs \\
\hline Asplenia \\
\hline Howell-Jolly and Heinz bodies in the erythrocytes \\
\hline Malrotation of the gut \\
\hline Midline stomach \\
\hline Midline liver \\
\hline Bilateral minor fissures of lungs (tri-lobed lungs) \\
\hline Bilateral eparterial bronchi \\
\hline
\end{tabular}

was consulted for veno-arterial extracorporeal membrane oxygenation (ECMO) support. Palliative B-T shunt placement was also arranged a few days later.

\section{Discussion}

Viscero-atrial heterotaxia associated with asplenia or polysplenia, known as heterotaxy or Ivemark syndrome, was first reported by the Swedish pediatrician Ivemark in 1955 [3]. Incidence of heterotaxy syndrome is very low, estimated at 1 in 6000 to 20,000 live births $[1,2]$. The pathogenesis of heterotaxy syndrome arises from abnormal laterality of the internal organs during fetal development. Genetic and environmental factors may play important roles in its pathogenesis; inheritance, chromosomal translocation or deletion, and gene mutation had been discussed [3-6]. Localization of the spleen, is often indicative of the type of lateralization abnormality. There are two subtypes for heterotaxy syndrome: polysplenia with bilateral left-sidedness and asplenia with bilateral right-sidedness, which are also called left isomerism and right isomerism, respectively. Heterotaxy syndrome is usually associated with major cardiac malformations, which determine the clinical presentation and mortality. These anomalies may lead to a mortality of $61 \%$ in patients with left isomerism and $80-95 \%$ in those with right isomerism in the first year of life if without prior surgical correction [7-9]. Palliative cardiac surgery may improve the survival rate, particularly during infancy [9].

The cardiac anomalies in cases with asplenia tend to be more severe than in polysplenia. Asplenia is frequently accompanied with functional univentricular hearts, complete atrioventricular canal defects, anomalous pulmonary venous drainage, obstruction to pulmonary outflow, bilateral superior vena cava, and interruption of the inferior vena cava [10]. All the above anomalies could be found in our patient (Table 1 \& Figure 1). In addition, there are extracardiac anomalities, including intestinal malrotation, midline liver, trilobulated left lung, asplenia; rarely, fused adrenal glands, hypoplastic or horseshoe kidney, and anal atresia [11]. Morphologic anomalies of peripheral red blood cells, such as HJ bodies, are evidence of a nonfunctional spleen which failed in filtrating abnormal erythrocytes, such as $\mathrm{HJ}$ bodies, from the circulation.

The clinical presentation and surgical options of the cardiovascular anomalies can vary dramatically depending on the relationship between the great arteries and the VSD. Patients with DORV and hypoplasia of main pulmonary trunk must be palliated by modified $\mathrm{B}$-T shunt to augment the pulmonary flow for survival. This procedure is a temporarily maneuver used to relieve cyanosis while the infant is waiting for corrective surgery. The prognosis of uncorrected univentricular hearts are usually poor, and their median survival time are usually limited to 14 years (death rate of $4.8 \%$ per year) [12]. However, there were reports on patients with single ventricle who have survived to adulthood without surgery. These patients usually have a perfectly balanced pulmonary circulation [13]. Long term survival for patients with univentricular hearts depends on achieving a balance between relieving pulmonary volume overload and providing sufficient pulmonary blood flow to oxygenate the blood [14].
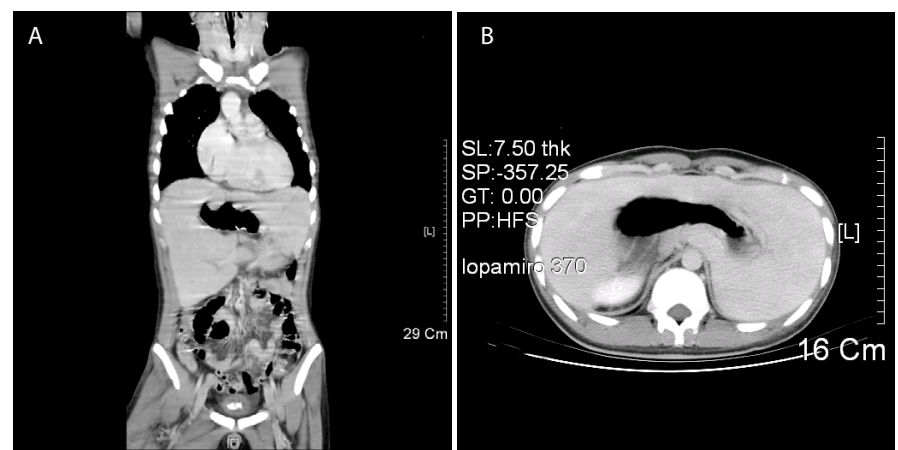

Figure 2. Abdomen CT showed the centrally-located stomach and midline liver. Coronal section(A) and cross section (B)
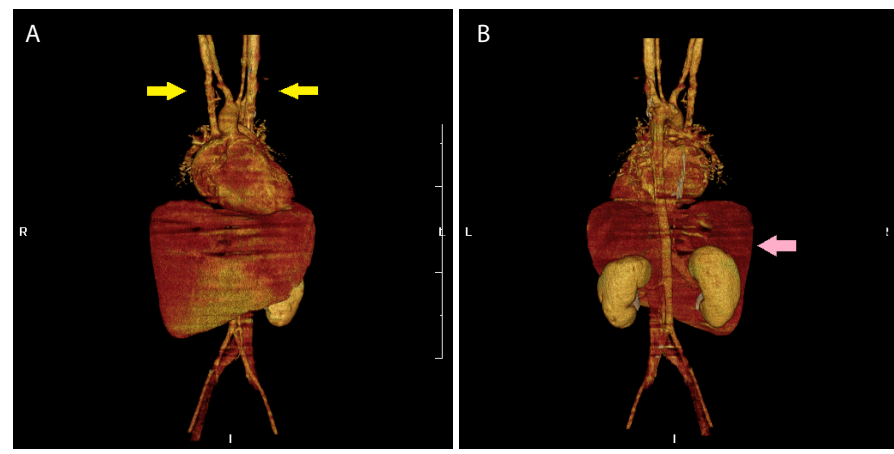

Figure 3. Reconstructive sixty four slices CT revealed (A) bilateral superior vena cava (SVC), yellow arrow, and (B) agenesis of the spleen and midline liver, pink arrow. 
The B-T shunt maintaining a balanced pulmonary circulation was very essential for patient with univentricular heart. Severe hypoxemia developed in our patient could be the result of nonfunctional B-T shunt after the trauma. Total occlusion of the B-T shunt was noted both on images of sixty four slices CT and cardiac catheterization. Our patient was at increased risk of thromboembolic events because of multiple risk factors including erthrocytosis, fat emboli released from fractured long bone, sympathetic stimulation, and hemoconcentration after dehydration. Other causes of hypoxemia included increased pulmonary vascular resistance and decreased pulmonary blood flow due to hypoxia, hypercarbia, acidosis and increased catecholamine release following stress and pain. As thromboembolism could be present in any trauma patient, a functional B-T shunt became a life saving factor in our patient. Patient under this condition should be admitted to intensive care unit and surgery should be postponed until preoperative evaluation of cardiac function and patency of B-T shunt is confirmed. Preoperative echocardiography and catheterization could provide medical staff with information on these conditions. The principle of anesthetic management included maintenance of systemic vascular resistance to avoid an increase in the right-to-left shunt, maintenance of adequate pulmonary blood flow, and preserving ventricular function [15] (Table 1).

Pre-anesthetic evaluation for emergency surgery is often under tight time constrain which might lead to overlook of laboratory data or patient's conditions. In this case, the decision to postpone surgery to observe for DICH had prevented us from giving anesthesia to a patient with Ivemark syndrome. In fact, an opportunity to review the patient's medical history and performing more thorough physical examination would facilitate early diagnosis of patient's underlying condition. Cyanotic lips, clubbing fingers, precordial scars of previous open-heart surgery, and heart murmurs, secondary polycythemia with microcytic cells on the hemogram, extraordinary cardiac shadow and centrally located gastric bubble on the plain chest film (Figure. 1) were all indications of a congenital heart disease complicated with chronic hypoxemia. Total occlusion of B-T shunt may happen during stressful condition leading to reduced or near no flow entering the pulmonary circulation. In such conditions, extracorporeal circulation (ECC) will be very essential. Therefore, transfer of patient to hospitals equipped with ECC support should be considered once the patient's condition is being stabilized.

In conclusion, we cannot reiterate enough the importance of pre-anesthetic evaluation. A functional palliative shunt became a life saving factor for patients with univentricular heart [16]. Secondary polycythemia, trauma, sympathetic stimulation, dehydration, and fat embolism will all increase the risk of thromboembolic events, which may also cause occlusion of palliative shunt, and worsen the condition of hypoxemia. Therefore, to ensure a functioning palliative shunt perioperatively is a matter of concern for anesthesiologist when treating these patients.

\section{Conflict of interest}

We declared that there is no conflict of interest exist for all the authors stated above and support for this study is only from departmental only.

\section{References}

1. Roth P, Agnani G, Arbez-Gindre F, Roux C, Martin A, et al. (1993) [Ivemark syndrome: 2 case reports]. J Gynecol Obstet Biol Reprod (Paris) 22: 771-775. [Crossref]

2. Britz-Cunningham SH, Shah MM, Zuppan CW (1995) Mutations of the Connexin43 gap-junction gene in patients with heart malformations and defects of laterality. $N E n g l$ J Med 332: 1323-1329. [Crossref]

3. Chen WC, Tsai FJ, Wu JY, Shi YR, Wu HC (2000) Mutation analysis of human LEFTY A and LEFTY B genes in children with Ivemark syndrome. Acta Paediatr Taiwan 41: 259-262. [Crossref]

4. Belmont JW1, Mohapatra B, Towbin JA, Ware SM (2004) Molecular genetics of heterotaxy syndromes. Curr Opin Cardiol 19: 216-220. [Crossref]

5. Ware SM (2006) DNA mutation analysis in heterotaxy. Methods Mol Med 126: 247256. [Crossref]

6. Ware SM, Peng J, Zhu L, Fernbach S, Colicos S, et al. (2004) Identification and functional analysis of ZIC3 mutations in heterotaxy and related congenital heart defects. Am J Hum Genet. 74: 93-105. [Crossref]

7. Cesko I, Hajdú J, Marton T, Tarnai L, Zs Tóth E (1998) [Familial heterotaxy syndrome. Case report and review of the international literature]. Orv Hetil 139: 2775-2778. [Crossref]

8. Chen WC, Tsai FJ, Wu JY, Wu HC, Li CW (2000) Does Ser364Pro mutation of connexin 43 exist in Taiwanese patients with Ivemark syndrome? Zhonghua Yi Xue Za Zhi (Taipei) 63: 691-695. [Crossref]

9. Gilljam T, McCrindle BW, Smallhorn JF, Williams WG, Freedom RM (2000) Outcomes of left atrial isomerism over a 28 -year period at a single institution. $\mathrm{J} \mathrm{Am}$ Coll Cardiol 36: 908-916. [Crossref]

10. Sapire DW, Ho SY, Anderson RH, Rigby ML (1986) Diagnosis and significance of atrial isomerism. Am J Cardiol 58: 342-346. [Crossref]

11. Hashmi A, Abu-Sulaiman R, McCrindle BW, Smallhorn JF, Williams WG, et al. (1998) Management and outcomes of right atrial isomerism: a 26-year experience. $J$ Am Coll Cardiol 31: 1120-1126. [Crossref]

12. Simpson J, Zellweger H (1973) Familial occurrence of Ivemark syndrome with splenic hypoplasia and asplenia in sibs. J Med Genet 10: 303-304. [Crossref]

13. Rothmaler G, Gdanietz K, Peschel HG (1968) [The Ivemark syndrome. 7 own cases and review of literature]. Arch Kinderheilkd 177: 74-97. [Crossref]

14. Moodie DS, Ritter DG, Tajik AJ, O'Fallon WM (1984) Long-term follow-up in the unoperated univentricular heart. Am J Cardiol 53: 1124-1128. [Crossref]

15. Michelakis N, Makaryus AN, Rosman D, Kort S (2004) Assessment of intracardiac anomalies in two adults with Ivemark's syndrome. J Am Soc Echocardiogr 17: 12921296. [Crossref]

16. Jinyoung S, I-Seok $\mathrm{K}$, June $\mathrm{H}$, et al. (2013) Interstage mortality for functional single ventricle with heterotaxy syndrome: a retrospective study of the clinical experience of a single tertiary center. J Cardiothorac Surg 8: 93. [Crossref]

Copyright: (C2017 Chen LW. This is an open-access article distributed under the terms of the Creative Commons Attribution License, which permits unrestricted use, distribution, and reproduction in any medium, provided the original author and source are credited. 